\title{
Contaminant-Organic Complexes, Their Structure and Energetics in Surface Decontamination Processes
}

(Project Number: 64947)

\section{Principal Investigator}

Calvin C. Ainsworth

Pacific Northwest National Laboratory

P.O. Box 999, MSIN K3-61

Richland, WA 99352

(509) 375-2670 (phone)

(509) 3725-6954 (fax)

calvin.ainsworth@pnl.gov

\section{Co-Investigators}

Benjamin P. Hay

Pacific Northwest National Laboratory

P.O. Box 999, MSIN K1-83

Richland, WA 99352

(509) 372-6239 (phone)

(509) 375-6631 (fax)

benjamin.hay@pnl.gov

Samuel J. Traina

Ohio State University

School of Natural Resources

2021 Coffey Road

Columbus, $\mathrm{OH} 43210$

(614) 292-9037 (phone)

(614) 292-7432 (fax)

traina.1@osu.edu

Satish C. B. Myneni

LBNL, Earth Sciences Division

Mail Stop 50E

Berkeley, CA 94720

(510) 486-4591 (phone)

(510) 486-5105 (fax)

smyneni@lbl.gov 


\section{Research Objective}

There are many compounds that are naturally occurring biodegradable organic chelates (siderophores) and appear to be more effective at oxide dissolution and actinide complexation than ethylenediaminetetraacetic acid (EDTA) or other organic acids currently used in decontamination processes. These chelates bind hard acids [Fe(III) and actinides(IV)] with extraordinarily high affinities. For example, the binding constant for the siderophore enterobactin with iron is about $10^{50}$, and its binding constant for $\mathrm{Pu}(\mathrm{IV})$ is estimated to be as high. Hence, this project is investigating the efficacy of using siderophores (or siderophore-like chelates) as decontamination agents of metal surfaces. The specific goals of this project are as follows:

- To develop an understanding of the interactions between siderophores (and their functional moieties), Fe and actinide oxides, their surface chemical properties that foster their dissolution and the conditions that maximize that dissolution.

- To develop the computational tools necessary to predict the reactivity of different siderophore functional groups toward oxide dissolution and actinide (IV) solubilization.

- To identify likely candidate chelates for use in decontamination processes.

To meet these objectives, the project combines x-ray absorption spectroscopy (XAS) and computational chemistry to provide basic information on the structure and bonding of siderophore functional groups to metal ( $\mathrm{Fe}$ and $\mathrm{U}$ ) oxide specimens common to corrosion products and scales on carbon steel and stainless steel encountered in DOE facilities. The project explores fundamental scientific aspects of oxide mineral surface chemistry and dissolution related to chelate-induced solubilization. The spectroscopic and computational aspects of this project are complemented by macroscopic dissolution and solubilization studies of oxides and associated contaminants. From this combination of molecular, macroscopic, and computational studies, structure-function and structure-reactivity relationships will be developed. These tasks are centered on investigative themes: 1) macroscopic dissolution studies (C. Ainsworth, PNNL), 2) optical spectroscopy (C. Ainsworth [PNNL]), 3) x-ray absorption spectroscopy (XAS) (S. Traina [OSU] and S. Myneni [LBNL]), and 4) computational chemistry (B. Hay [PNNL]).

\section{Research Progress and Implications}

This report summarizes research after 1.5 years of a three-year project. Initial investigations have centered on dissolution, computational chemistry, and XAS; XAS results are not reported here.

Dissolution studies to date have concentrated on the hydroxamic acid-type ligands with one, two, and three hydroxamate functional groups; acetohydroxamate; rhodotorulic acid; and desferrioxamine B. Batch-type $\mathrm{pH}$-statistics investigations have shown that dissolution rates of iron oxides (geothite, hematite, and magnetite) increase by more than an order of magnitude as 
the number of functional groups per molecule increase (i.e., acetohydroxamate, rhodotorulic acid, and desferrioxamine B) even though the total concentration of hydroxamic acid groups remain constant. Unlike oxide dissolution in the presence of ethylenediaminetetraacetic acid (EDTA), the iron oxide dissolution rate appears to decrease linearly as $\mathrm{pH}$ is increased from 4.5 to 9.0. This suggests that, unlike EDTA, there is limited binuclear adsorption of the ligand or readsorption of the dissolved iron-siderophore at low $\mathrm{pH}$ when the surface is positively charged.

An extended molecular mechanics MM3 model has been developed for Fe(III) complexes with catecholamides. Assignment of Fe-O stretch, Fe-O-C bend, and Fe-O-C-C torsion parameters was based on geometries and potential energy surfaces from density functional theory calculations and crystal structure data and were investigated at the MP2 level of theory. These included rotational potential surfaces for several C-C bond types and hydrogen bonds involving phenol. The result models empirical relationships between force constants and physical properties. In addition to these metal-dependent interactions, several unknown intra-ligand interactions reproduce crystal structures with the expected level of accuracy. By changing only the M-O stretching parameters, a good agreement between calculation and experiment is obtained for other metal ions. In addition, we found that this model is applicable to tropolonate complexes. Published barriers to octahedral inversion are reproduced to within $\pm 2 \mathrm{kcal} / \mathrm{mol}$ for $\left.[\mathrm{Al}(\mathrm{III}) \text { (tropolonate })_{3}\right]$ and $\left[\mathrm{Ga}(\mathrm{III})(\text { catecholamide })_{3}\right]^{3-}$.

Applying this model led to the first quantitative structure-activity relationship for catecholamide ligands. Conformational searches yielded the lowest-energy forms of the sixprotonated ligands shown in Figure 1. Conformational searches were also run to identify the lowest-energy forms of their Fe(III) complexes. We obtained the difference in steric energy between the Fe-L complex and the hexaprotonated ligand. A plot of pFe versus this energy difference yields a highly significant linear correlation. The result suggests that this method can be used to screen other candidate architectures for ligands based on the catecholamide donor group.

\section{Planned Activities}

Dissolution studies will focus on catecholamide siderophores that have been isolated from selected organisms. In addition, several catecholates are being synthesized to systematically test the MM3 model discussed above. Investigations will continue to focus on the Fe oxides (geothite, hematite, and magnetite). However, studies of $\mathrm{UO}_{2}$ dissolution will begin at the end of this year and continue in the final year of this project. Modeling efforts will continue to expand to include the hydroxamate siderophores. To date, the optical spectroscopy investigations have not progressed as anticipated but will continue, and these efforts will be integrated with the XAS investigations of S. Traina and S. Myneni. 
<smiles>[R]NC(=O)C(COC(=O)C(COC(=O)C(COC(=O)[C@H](N[R])N[2H])N[R])N[2H])N[R]</smiles>

Enterobactin

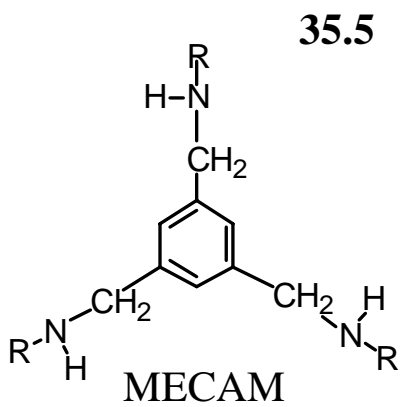

29.4<smiles>[R]NCc1c(CC)c(CNP)c(CC)c(CNP)c1CC</smiles>

32.6

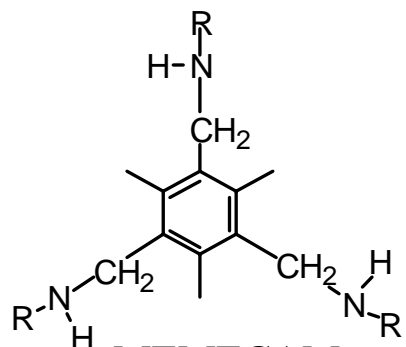

31.2<smiles>[R]NCCN(CCNP)CCNP</smiles>

TRENCAM

27.8<smiles>[R]N(C)CCCCN([R])CCCCN([R])CCC</smiles>

CYCAM<smiles>CC(=O)c1cccc(O)c1O</smiles>

Figure 1. Six Tris-Catecholamide Siderophore Architectures Have Been Examined Using the Developed Model. Relative affinities for Fe(III) are given as pFe values (10 $\mu \mathrm{M}$ ligand, $1 \mu \mathrm{M} \mathrm{Fe}(\mathrm{III})$, and $\mathrm{pH}$ 7.4). 